\section{Early Neolithic agriculture in Southwest Asia and Europe: re-examining the archaeobotanical evidence Sue Colledge \& James Conolly}

Agriculture is widely recognized as a defining characteristic of the Neolithic period in Southwest Asia and Europe, but, despite many years of research, and the discovery of much new archaeobotanical evidence, there have been few attempts to investigate its origins and spread in the region as a whole. Now, in a new project at the Institute of Archaeology, the scattered evidence for the emergence and dispersal of crops is being systematically assessed and documented both spatially and chronologically.

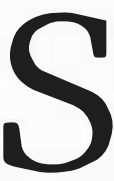

ome 40 years ago the pioneer archaeobotanist Hans Helbaek emphasized the importance of correctly dated plant remains as a means of investigating the relationship between "man and nature", ${ }^{1}$ and he later developed a technique for separating charred plant materials from the sediments in which they had been preserved. ${ }^{2}$ Although many archaeobotanical investigations have been carried out since then at Neolithic sites in Southwest Asia and Europe, we still lack a database that is sufficiently large, systematic and well founded to enable us to gain a better understanding of the emergence and spread of agriculture in the region.

In July 2001 a new three-year project ${ }^{3}$ was started at the Institute with the aims of collecting, assessing and systematically recording in a chronological frameworkall the available data on the plant remains (mainly charred seeds) that have been recovered from early Neolithic and Epipalaeolithic or Mesolithic sites in the region. ${ }^{4}$ In this article, we describe the background to the project and outline some of our preliminary findings. After only a few months work, and having not yet begun to consider any early Neolithic sites in Europe, we have surprising new evidence indicating that at least one site (Jericho), hitherto accepted as providing evidence of some the earliest domesticated crops, has been inaccurately interpreted. We have therefore to reconsider the questions of where and when crops first appear in the archaeological record of Southwest Asia.

The origins of domestic crops in the Southwest Asian Fertile Crescent ${ }^{5}$

As the European icesheets began to retreat at the end of the most recent ice age soon after 18,000 years ago, the climate slowly became wetter and warmer. This gradual amelioration was punctuated by much colder and drier periods, lasting for at most a thousand years or so, and the distribution and composition of the natural vegetation cover altered significantly in response to the changes in temperature and humidity. Although the effects on the landscape of these changes were most noticeable in northern latitudes, they were also apparent to a lesser degree worldwide. The impact of the cold spells, in particular, had profound consequences for how people adapted to, and interacted with, their environments.

Semi-sedentary Natufian groups of hunter-gatherers inhabited much of the Levant ${ }^{6}$ when the climate was at its warm est and wettest during the so-called climatic optimum some 12,500 years before present (c. 12,500 bp). They benefited from increased local availability of the plant foods they had come to rely on, such as the grains of wild cereal grasses, as is indicated by mortars and pestles forgrinding them and other possible processing tools found at Natufian sites. About 1500 years later, the Natufians experienced a sudden change of climate to much colder and drier conditions (a period referred to as the YoungerDryas, $c .11,000$ to $c .10,000$ bp), which caused their supplies of wild plant foods to diminish. It is probable that, as a direct result of this change, they attempted some form of management of the wild plants that had become staples in their diet. Thus, it is thought, the first attempts to cultivate wild cereals took place. By sowing the wild grains in tilled fields, the Natufians ensured that they had annual harvests sufficient for their needs and they gained some control over the supplies of plant foods regardless of climatic instability. Domestic species of cereals evolved as a result of the cultivation of the wild forms. This led to the selection of plants with tough rachises ${ }^{7}$ that prevented the separate spikelets, which enclose the grains, from shedding naturally once ripe.

We encounter the earliest evidence of the domestic crops on which Neolithic agriculture was founded in the Fertile Crescent during the period referred to as the Pre-Pottery Neolithic A or PPNA ( $c$. 10,200 to $c .9500 \mathrm{bp}$ ), soon after the first experiments at cultivation had apparently taken place a few hundred years earlier.

There were eight founder crops, three of which were cereals (barley, einkorn and emmer wheat), four were pulses (lentil, pea, chickpea and bitter vetch), and one was a fibre plant (flax). It is thought that the cereals were domesticated first and that the other species evolved at about the same time or possibly somewhat later. ${ }^{8}$

Our knowledge of the evolution and spread of the founder crops depends on the examination and accurate identification of charred grains found in samples recovered from securely dated occupation levels at early Neolithic sites. The reported presence, or absence, at different localities and times of domestic species (when correctly identified as such) has provided the evidence for our understanding of the distribution of the earliest crops and of their subsequent dispersal throughout Southwest Asia. But this procedure is not without its pitfalls, as the example of Jericho shows.

\section{Jericho revisited}

Very few PPNA sites in Southwest Asia have yielded evidence of domestic cereals; to varying degrees, the finds from them are controversial. The domestic wheat and barley found in the PPNA levels at Jericho are no exception to this.

The large mound at Jericho - a tell about $20 \mathrm{~m}$ high, $320 \mathrm{~m}$ long and $140 \mathrm{~m}$ wide represents several thousand years of occupation. Kathleen Kenyon excavated at Jericho in the early 1950s when she was a member of staff of the Institute, and in the largest of her trenches she dug down to the earliest occupation layers of the settlement and exposed the full extent of a massive stone-built tower and walls that were first constructed during the PPNA (Fig. 1). ${ }^{9}$ Together with fragments of burnt plaster

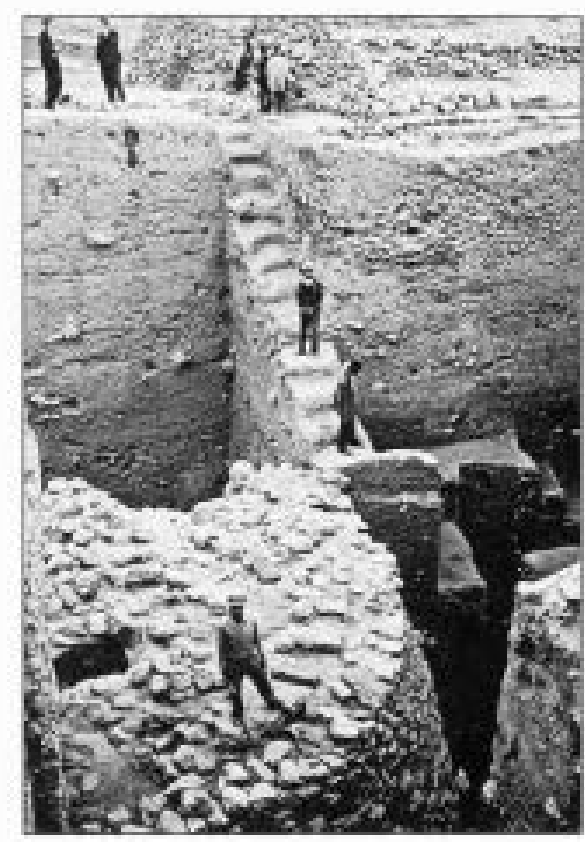

Figure 1 Part of the circular tower at Jericho (front left), with a deep excavated section beyond showing the deposits that accumulated around the tower during the Pre-Pottery Neolithic A period. 


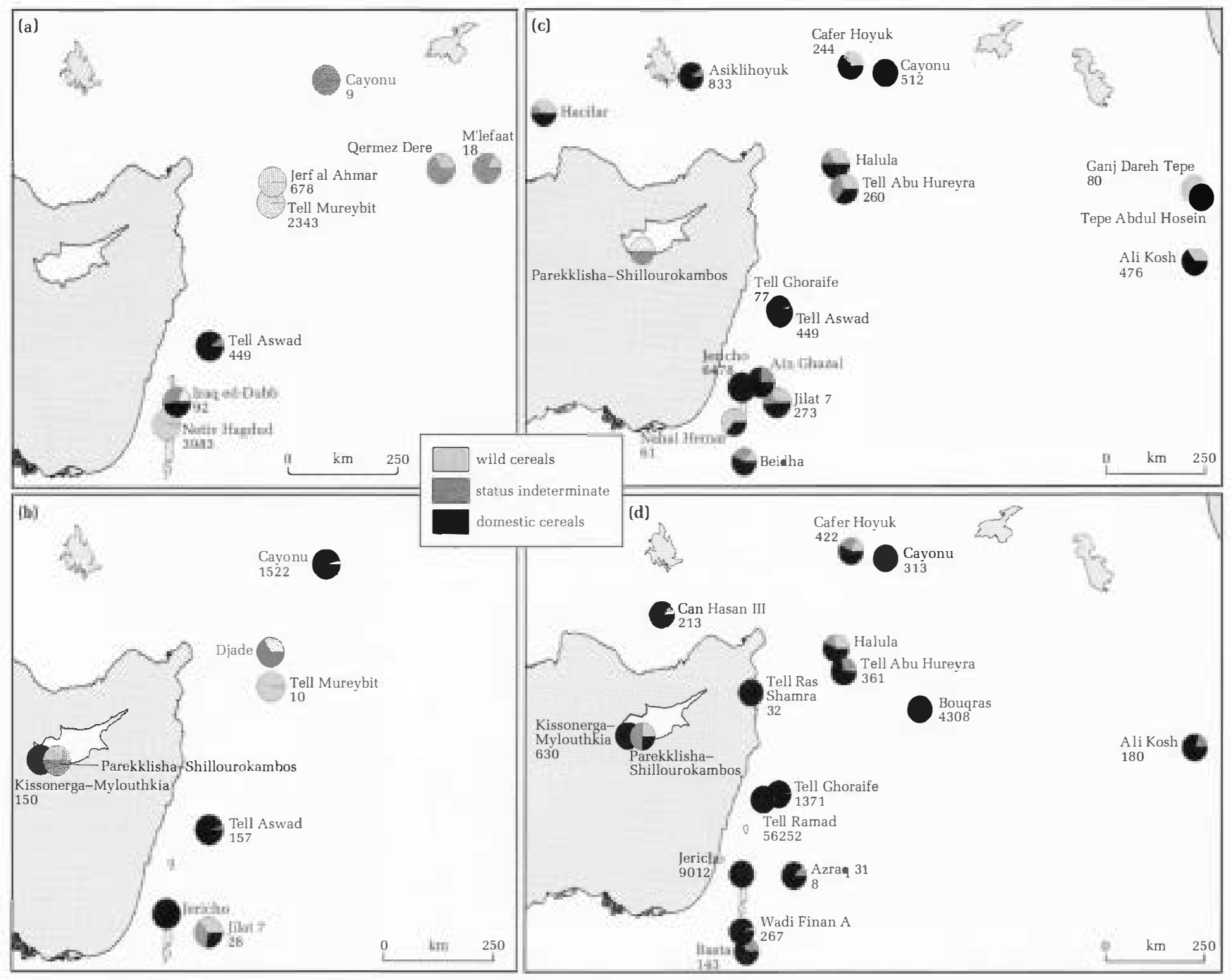

Figure 2 The distribution of early Neolithic sites in the Fertile Crescent, southeastern Anatolia and Cyprus; the changing proportions of wild and domestic cereals identified at them have been calculated for each period: (a) PPNA, 10,200-9500 bp; (b) Early PPNB, 9500$9200 \mathrm{bp}$; (c) Middle PPNB, 9200-8500 bp; (d) Late PPNB, 8500-8000. The numbers by the site names refer to the total quantity of cereal remains (seeds and chaff) identified. Such information is lacking for the sites without numbers.

that bore the impressions of grains, samples of charred plant remains were taken for analysis from the deposits adjacent to the walls. ${ }^{10}$ Domestic einkorn and emmer wheat and domestic barley (the three founder-crop cereals) were identified in these PPNA contexts. ${ }^{11}$ However, our closer examination of the relationship between these finds and the radiocarbon dates of the layers with which they were associated has shown that the cereal remains were chronologically contemporary with the succeeding Early Pre-Pottery Neolithic B phase (c. 9500-9200 bp). ${ }^{12}$ Therefore, we should probably no longer regard the domestic cereals found at Jericho as among the earliest known, although (no less significantly) they may represent evidence for the initial stages of dispersal from their areas of origin elsewhere in the region.

This reassessment of the archaeobotanical evidence from Jericho suggests that maps showing the areas of origin and subsequent spread of the founder crops during the PPNA and PPNB may need to be redrawn. Figure 2 shows the results of our first attempts at reconstructing the changing proportions of wild and domestic cereals found at PPNA and PPNB sites around the Fertile Crescent. Wild cereals predominate in a majority of the PPNA (phase 1) sites, whereas at the few Early PPNB (phase 2) sites, the pattern is reversed, with most of them having more domestic cereals. This trend continues during the Middle and Late PPNB (phases 3 and 4), with increasing evidence for higher proportions of domestic crops at the more numerous sites now spread throughout the Fertile Crescent and extending west into south-central Anatolia.

\section{Modelling the spread of early farming in Europe}

Farming communities became established across Europe some time after their initial appearance in the Fertile Crescent, and the dates of their settlements become progressively later as the distances from the Southwest Asian heartland increase. The founder crops (and domestic animals) that evolved in Southwest Asia formed the basis of the so-called Neolithic farming package that disseminated throughout continental Europe and across the sea to Britain and Ireland. Whether it was the Neolithic farmers themselves who spread, or their crops and the knowledge and technology to grow them, or some combination of both, is hotly and at times acrimoniously debated. The timing and tempo of this Neolithic diaspora has been the subject of much research over the past 30 years.

A major source of evidence that has been used in the past to investigate the process of dispersal across Europe has been the chronology of the first appearance of farming communities. Grahame Clark was the first to attempt this, in 1965. ${ }^{13} \mathrm{He}$ established that the initial 
spread of farming took place along the Danube, thus confirming the earlier work by Gordon Childe that was undertaken without the benefit of radiocarbon dating. ${ }^{14}$ Then, in 1971, Ammerman \& CavalliSforza proposed a statistical model for the expansion of farming. ${ }^{15}$ They found that, although a general rate of progression of about $1 \mathrm{~km}$ per year (from an assumed origin at Jericho) explained the spread of the Neolithic across Europe reasonably well, there were areas that deviated substantially from this average, notably the Linear Pottery (Bandkeramic) culture of central Europe, which evidently spread at rates in excess of $5 \mathrm{~km}$ a year. Based on this evidence, and despite identifying territories into which the Neolithic moved at a rate faster or slower than the average, they concluded that the best explanation for the overall pattern of movement was a demic diffusion caused by population expansion, which resulted eventually in the replacement, by incoming Neolithic farmers, of indigenous Mesolithic huntergatherers.

However, later research has muddied the waters. The spatial and temporal patterns of Neolithic expansion identified by Ammerman \& Cavalli-Sforza were shown to be as easily accounted for by population diffusion (e.g. through intermarriages between hunter-gatherer and early farming groups) or by cultural diffusion independent of population movements. ${ }^{16}$ Genetic analysis of modern Europeans has shown the importance of pre-Neolithic populations in the contemporary gene pool,${ }^{17}$ and more sophisticated analysis of the radiocarbon record has shown that the relationship between the decline of indigenous Mesolithic populations and the first appearance of farming communities is varied and at times ambiguous. ${ }^{18}$ Now the consensus of opinion is that some mixture of demic expansion, diffusion, and the adoption of cultural traits was responsible for the spread of the Neolithic into and across Europe, but debate still continues as to which of these processes were effective in different regions. ${ }^{19}$

Evidence used in debates on the neolithization of Europe is still mainly based on the analysis of radiocarbon dates from late Mesolithic and early Neolithic sites. It is surprising that the most direct evidence for the spread of farming communities the remains of their crops - has not been incorporated systematically into any of the existing models. Yet archaeobotanical data, when classified spatially and temporally, can give us the clearest evidence not only of when crops first appeared in any given region but also about the ecological characteristics of early farming practices. It is for these reasons that our first priority is to establish an archaeobotanical database containing details of the wild and domestic plants found on pre- and early Neolithic sites in both Southwest Asia and Europe, which will be linked to the most recent radiocarbon database of such sites in Europe. ${ }^{20}$ This, in turn, will be linked to GIS (geographical information system) map data of topographic, soil, temperature and rainfall patterns across Europe. The overall objective is to model the spatial, temporal and ecological contexts of the first appearance and dispersal of plant domesticates, which will contribute greatly to our understanding of the complex processes by which crops, early farming practices and Neolithic peoples spread into Europe from their ecologically very different Southwest Asian homeland.

\section{Notes}

1. He did so as early as 1960; see p. 9 in H. Helbaek, "The palaeoethnobotany of the Near East and Europe", in Prehistoric investigations in Iraqi Kurdistan, R. J. Braidwood \& B. Howe (eds), 99-118 (Chicago: University of Chicago Press, Studies in Ancient Oriental Civilization no. 31, Oriental Institute, University of Chicago, 1960).

2. See p. 385 in "Plant collecting, dry farming, and irrigation agriculture in prehistoric Deh Luran", in Prehistory and human ecology of the Deh Luran plain, F. Hole, K. V. Flannery, J. A Neely (eds), 383-426 (Memoir 1, Museum of Anthropology, University of Michigan, 1966).

3. The project, entitled "The origin and spread of Neolithic plant economies in the Near East and Europe", is supported by a grant from the UK Arts and Humanities Research Board. Stephen Shennan is the principal investigator, and James Conolly and James Steele (of Southampton University) are co-investigators. The project is one of the research initiatives at UCL taken by the Centre for the Evolutionary Analysis of Cultural Behaviour, directed by Stephen Shennan.

4. The term "Epipalaeolithic" refers to the final part of the Palaeolithic period in Southwest Asia that immediately preceded the Neolithic. In Europe the term "Mesolithic" is used for the equivalent pre-Neolithic period.

5. The Fertile Crescent refers to the upland arc that stretches from the southern Levant north and east around the Mesopotamian lowland and southeast along the foothills of the Zagros mountains in western Iran.

6. The people known as Natufians occupied sites throughout the Levant, from the mid dle Euphrates valley in the north to the highlands of the Negev in the south, and east across the Jordanian plateau.

7. The rachis is the "spine" of the cereal ear. In wild cereals the rachis is brittle and the separate spikelets containing the seeds shed naturally once the plants are ripe. In the process of domestication selection favoured plants with tough rachises, to which the spikelets remained firmly attached even when the ears were ripe. Thus, the domesticated cereals could not survive without the intervention of the early Neolithic farmers, who had to reap and sow the grains to guarantee annual harvests.

8. See D. Zohary, "The mode of domestication of the founder crops of Southwest Asian agriculture" in The origins and spread of agriculture and pastoralism in Eurasia, D. R. Harris (ed.), 142-58 (London: UCL Press, 1996), and D. Zohary, "Monophyletic versus polyphyletic origin of the crops on which agriculture was founded in the Near East", Genetic Resources and Crop Evolution46, 133-42, 1999.

9. Kathleen Kenyon undertook seven campaigns at Jericho between 1952 and 1958; see Excavations at Jericho, vol. nII: the architecture and stratigraphy of the tell. (text), K. Kenyon \& T. A. Holland (eds) (London: BritishSchool of Archaeology in Jerusalem, 1981).

10. See plates 236 and 238 in Excavations at Jericho, vol. III: the architecture and stratigraphyof the Tell (plates), K. Kenyon \& T. A. Holland (eds) (London: British School of Archaeology in Jerusalem, 1981).

11. M. Hopf, "Appendix B: Jericho plant remains", in Excavations at Jericho, vol. 5: the pottery phases of the tell and other finds, K. M. Kenyon \& T. A Holland (eds), 576-621 (London: British School of Archaeology in Jerusalem, 1983).

12. O. Bar-Yosef \& A. Goren suggest that the radiocarbon dates from Jericho indicate that the PPNA lasted there from $c .10,300$ bp to 9300-9200 bp; see p. 257 in An early Neolithic village in the Jordan valley, part 1: the archaeology of Netiv IIagdud, O. Bar-Yosef \& A. Goren (eds) (Bulletin 43, American School of Prehistoric Research, Peabody Museum of Archaeology and Ethnology, Harvard University, 1997).

13.J.G.D.Clark, "Radiocarbon dating and the expansion of farming culture from the Near East over Europe", Proceedings of the Prehistoric Society 31, 57-73, 1965.

14. V. G. Childe, The Danube in prehistory (Oxford: Oxford University Press, 1929).

15.A. J. Ammerman \& L. L. Cavalli-Sforza, "Measuring the rate of spread of early farming in Europe", Man (new series) 6, 674-88, 1971.

16. K. Aoki, M. Shida, N. Shigesada, "Travelling wave solutions for the spread of farmers into a region occupied by huntergatherers", Theoretical Population Biology 50, 1-17, 1996.

17. See, for example, M. B. Richards, V. A. Macaulay, H. J. Bandelt, B. C. Sykes, "Phylogeography of mitochondrialDNAin western Europe", Annals of IIuman Genetics 67, 1251-76, 1998.

18. M. Gkiasta, T. Russell, S. Shennan, J. Steele, Origins of Europeanagriculture: the radiocarbon record revisited, unpublished manuscript, UCL Institute of Archaeology, 2000.

19. See for example P. Bellwood, 2001. "Early agriculturalist population diasporas? Farming, language, and genes", Annual Review of Anthropology 30, 191-207, 2001, and M. Nowak, "The second phase of Neolithization in east-central Europe", Antiquity 75, 582-92, 2001.

20. See Gkiasta et al., cited in n. 19 above. 